Editorial

\title{
New Perspectives in the Definition/Evaluation of Seismic Hazard through Analysis of the Environmental Effects Induced by Earthquakes
}

\author{
Sabina Porfido ${ }^{1,2}\left(\mathbb{D}\right.$, Giuliana Alessio $^{2}\left(\mathbb{D}\right.$, Germana Gaudiosi $^{2}$ and Rosa Nappi ${ }^{2, *(1)}$ \\ 1 Consiglio Nazionale delle Ricerche - ISA - Via Roma 64, 80100 Avellino, Italy; sabina.porfido@cnr.it \\ 2 Istituto Nazionale di Geofisica e Vulcanologia - Sezione di Napoli Osservatorio Vesuviano. Via Diocleziano, \\ 328, 80124 Napoli, Italy; giuliana.alessio@ingv.it (G.A.); germana.gaudiosi@ingv.it (G.G.) \\ * Correspondence: rosa.nappi@ingv.it
}

Received: 31 January 2020; Accepted: 31 January 2020; Published: 4 February 2020

check for updates

\begin{abstract}
The application of the Environmental Seismic Intensity (ESI) scale 2007 to moderate and strong earthquakes, in different geological context all over the word, highlights the importance of Earthquake Environmental Effects (EEEs) for the assessment of seismic hazards. This Special Issue "New Perspectives in the Definition/Evaluation of Seismic Hazard through Analysis of the Environmental Effects Induced by Earthquakes" presents a collection of scientific contributions that provide a sample of the state-of-the-art in this field. Moreover the collected papers also analyze new data produced with multi-disciplinary and innovative methods essential for development of new seismic hazard models.
\end{abstract}

Keywords: ESI scale; earthquake environmental effects; seismic hazard

The devastating effects caused by the recent catastrophic earthquakes that took place all over the world from Japan, New Zealand, to Chile, as well as those occurring in the Mediterranean basin, have once again shown that the ground motion, although a serious source of direct damage, is not the only parameter to be considered, with most damage being the result of coseismic geological effects that are directly connected to the earthquake source or caused by ground shaking.

The primary environmental effects induced by earthquakes such as surface faulting, regional uplift, and subsidence, as well as the secondary effects such as tsunami, liquefaction, ground failure, and landslides (sensu Environmental Seismic Intensity (ESI) 2007 scale) [1], must be considered for a more correct and complete evaluation of seismic hazard, at both regional and local scales.

This Special Issue aims to collect all contributions that, using different methodologies, integrate new data produced with multi-disciplinary and innovative methods. These methodologies are essential for the identification and characterization of seismically active areas, and for the development of new hazard models, obtained using different survey techniques.

The topic attracted a lot of interest; moreover, different areas of the world have been analyzed through these methodologies (Italy, USA, Spain, Australia, Ecuador, Guatemala, South Korea, Kyrgyzstan, Mongolia, Russia, China, Japan, Nepal).

This Special Issue is composed of 18 peer-reviewed articles, out of 27 papers that had been received; different approaches to the evaluation of seismic hazard are presented in the volume, from laboratory tests on liquefaction phenomena and landslides triggered by earthquakes, to the analysis of the environmental effects (primary and secondary coseismic effects) induced by the earthquakes.

In detail, this Special Issue contains 5 review papers and 13 articles. Below is a brief description of the contents of all articles. 
- The review paper "History of the Environmental Seismic Intensity Scale ESI-07" by L. Serva [1,2] presents a brief note aiming to describe the history, from its early original idea, to the present of the new Environmental Seismic Intensity Scale 2007 (ESI 2007, Michetti et al., 2007). This innovative macroseismic scale can be used together with other existing scales or alone, if necessary, for measuring the intensity of an earthquake on the basis of the primary and secondary effects caused by the seismic event on the natural environment. The ESI 2007 scale was promoted by several geologists, seismologists, and engineers from different countries, forming a multidisciplinary international research group. This scale has been tested worldwide on several modern earthquakes, historical earthquakes, and paleoearthquakes. The review by Serva also presents a wide and comprehensive bibliography with the most important examples of ESI-07 scale applications carried out worldwide.

- The review paper "Paleoliquefaction Studies and the Evaluation of Seismic Hazard" by M.P. Tuttle et al. [3] presents recent and historical studies of earthquake-induced liquefaction, as well as paleoliquefaction studies, in order to demonstrate the potential usefulness of liquefaction data in the assessment of the earthquake hazard due to seismic sources. This paper presents background information on earthquake-induced liquefaction and the resulting soft-sediment deformation features that may be preserved in the geologic record, best practices used in paleoliquefaction studies, and the application of paleoliquefaction data in earthquake source characterization. The paper shows two examples of regional paleoliquefaction studies-in the Charleston seismic zone and the New Madrid seismic zone in the United States, respectively—which contributed to seismic source models used in earthquake hazard assessment.

- The review paper "Catalogue of the Geological Effects of Earthquakes in Spain Based on the ESI-07 Macroseismic Scale: A New Database for Seismic Hazard Analysis" by P.G. Silva et al. [4] summarizes the content and scope of the "Catalogue of Earthquake Geological Effects in Spain", published by the Geological Survey of Spain, and constitutes the first official publication on seismic hazard, containing geological information for this nation. The catalogue offers a variety of parametric information, quality indexes, and seismic intensity (ESI-07), with a description of environmental damage structured in individual "event files". Sixteen events present full information files with individualized analyses of the geological and geo-archaeological data as well as graphic information with hybrid Environmental Seismic Intensity-European Macroseismic Scale (ESI-EMS) intensity maps, shake maps, and complementary kmz files (Google Earth) among which is the well-known AD 1755 Lisbon earthquake-tsunami.

- The review paper "Surface-Rupturing Historical Earthquakes in Australia and Their Environmental Effects: New Insights from Re-Analyses of Observational Data" by T.R. King et al. [5] presents the digitization of surface rupture maps and compiles observational data from 67 publications on ten of eleven historical, surface-rupturing earthquakes in Australia, in order to analyze the prevailing characteristics of surface ruptures and other environmental effects in this crystalline basement-dominated intraplate environment. The authors have analyzed the earthquakes that occurred between 1968 and 2018, with a magnitude (Mw) from 4.7 to 6.6, and collected environmental effects including primary surface ruptures, secondary fracture/cracks, fissures, rockfalls, ground-water anomalies, vegetation damage, sand-blows/liquefaction, displaced rock fragments, and holes from collapsible soil failure, assessing the relative ESI-07 seismic intensity. This paper represents an important contribution that highlights Mw/ESI-07 relations in geologically different environments.

- The review paper "Post Seismic Catalog Incompleteness and Aftershock Forecasting" by E. Lippiello et al. [6] shows how standard models for earthquake forecasting can be modified to take into account this incompleteness, in particular, the authors focus on forecasting methods based on the data available in real time, in which many events are missing and the uncertainty in hypocenter location is considerable. Furthermore, the authors present retrospective tests that demonstrate the 
usefulness of these novel methods compared with traditional ones, which implement average values of parameters obtained from previous sequences.

- The paper "Landslides Triggered by the 2016 Mw 7.8 Pedernales, Ecuador Earthquake: Correlations with ESI-07 Intensity, Lithology, Slope and PGA-h" by K. Chunga et al. [7] presents a dataset of the landslides induced by the 2016 Pedernales megathrust earthquake in Ecuador (Mw 7.8, focal depth of $20 \mathrm{~km}$ ). The authors compare landslides spatial distribution with mapped bedrock lithology and horizontal peak ground acceleration (PGA-h) in order to evaluate the macroseismic intensity taking into account these earthquake-induced environmental effects (ESI-07). Moreover, the authors underline that coseismically-triggered landslides are among the most common environmental effects occurring during large subduction events, and they can be effectively used to properly evaluate the earthquake macroseismic field.

- The paper "The 1976 Guatemala Earthquake: ESI Scale and Probabilistic/Deterministic Seismic Hazard Analysis Approaches" by M. Caccavale et al. [8] shows how the hazard assessment of the 1976 Guatemala earthquake $(M=7.5)$ based on the environmental effects had effectively contributed to estimating the high destructive impact of that event. The results evidence that the probabilistic/deterministic hazard analysis procedures may result in very different indications on the PGA distributions, and PGA values often display significant discrepancy from the macroseismic intensity values calculated with the ESI scale. Therefore, the incorporation of the environmental geological effects into the probabilistic/deterministic hazard analysis appears to be mandatory in order to achieve a more accurate seismic hazard estimation.

- The paper "Geological and Structural Control on Localized Ground Effects within the Heunghae Basin during the Pohang Earthquake (MW 5.4, 15 November 2017), South Korea" by S.P. Naik et al. [9] presents the results of a systematic survey of the secondary ground effects, that is, soil liquefaction and ground cracks developed during the Pohang earthquake in South Korea $\left(\mathrm{M}_{\mathrm{w}}\right.$ $=5.4$ ) on 15 November 2017. The liquefaction phenomenon associated with the 2017 Pohang earthquake emphasizes that there is an urgent need of liquefaction potential mapping for Pohang city and other areas with a similar geological setting. The authors highlight that this phenomenon represents a hazard that may cause significant societal and economic threats in the future.

- The paper "Earthquake Environmental Effects of the $1992 \mathrm{M}_{\mathrm{S}}=7.3$ Suusamyr Earthquake, Kyrgyzstan, and Their Implications for Paleo-Earthquake Studies" by C. Grützner et al. [10] presents the application of the ESI-07 scale to the $1992 \mathrm{M}_{\mathrm{S}}=7.3$ Suusamyr Earthquake in the Kyrgyz Tien Shan. The author shows that the ESI-2007 intensity values distribution differs somewhat from traditional intensity assessments Medvedev-Sponheuer-Karnik (MSK) and Modified Mercalli Intensity scale (MMI), because of the sparse population in the epicentral area and the spatial distribution of primary and secondary Environmental Earthquake Effects (EEEs). However, the ESI-2007 scale captures a similar overall pattern of the intensity distribution. The final results highlight the applicability of this scale, even for earthquakes with complex and unusual primary surface rupture patterns.

- The paper "Earthquake-Induced Landslide Risk Assessment: An Example from Sakhalin Island, Russia" by Konovalov et al. [11] presents a new probabilistic technique for earthquake-induced landslide risk assessment. A fully probabilistic technique suggests a multi-stage hazard assessment; that is, an example from Sakhalin Island, Russia. The given approach follows the rational risk management idea that handles well all possible ground motion scenarios, slope models, and parameters. The authors suggest that the given approach can improve geotechnical studies of slope stability.

- The paper "Site Effect Assessment in Ulaanbaatar, Mongolia through Inversion Analysis of Microtremor H/V Spectral Ratios" by Z. Tumurbaatar et al. [12] presents the evaluation of a site effect, which is one of the essential parts of the earthquake hazard estimation, in Ulaanbaatar city, Mongolia, through inversion analysis of microtremor horizontal-to-vertical (H/V) spectral ratios. In this study, the $V_{S}$ models are estimated using microtremor data at 50 sites and inversion 
analysis is applied to the observed data in order to evaluate site amplifications in Ulaanbaatar city. In particular, the joint inversion technique based on a diffuse field approach is applied to estimate the $V_{S}$ structures at three sites using the observed horizontal-to-vertical $(\mathrm{H} / \mathrm{V})$ spectral ratios and surface wave phase velocities obtained by Odonbaatar (2011). The result shows that the largest site amplification zone is computed along the Tuul river in the southeastern part of Ulaanbaatar.

- The paper "Bayesian Variable Selection for Pareto Regression Models with Latent Multivariate Log Gamma Process with Applications to Earthquake Magnitudes" by H-C. Yang et al. [13] presents a Bayesian spatial variable selection for Pareto regression based on Bradley et al. and $\mathrm{Hu}$ et al. to tackle the variable selection issue in generalized linear regression models with spatial random effects. The authors demonstrate the applicability of the proposed method in an analysis of the earthquake data obtained from the United States Geological Survey (USGS).

- The paper "Machine Learning Methods for Seismic Hazards Forecast" by V.G. Gitis and A.B. Derendyaev [14] presents two machine learning methods for seismic hazard forecast. The first method is used for the spatial forecasting of maximum possible earthquake magnitudes (Mmax), whereas the second one is used for space-time forecasting of strong earthquakes. The authors show the results of testing the approach on earthquake prediction in the Mediterranean and Californian regions.

- The paper "Suitability Analysis for the Emergency Shelters Allocation after an Earthquake in Japan" by T. Akamatsu and K. Yamamoto [15] presents an applied statistical method and public open data related to population and emergency shelters, with the aim to quantitatively conduct a suitability analysis for the allocation of emergency shelters after an earthquake in Japan, in a GIS environment. The results show the districts that lack emergency shelters, and visually show the places where such facilities should be newly established on the digital map of GIS. Additionally, the assessment method is reproducible in the spatial and temporal dimension. However, it is necessary to create more original data related to emergency shelters to raise the reliability of the results, as the present research has the limitation of data availability.

- The paper “Use of Macroseismic Intensity Data to Validate a Regionally Adjustable Ground Motion Prediction Model" by Y. Tang et al. [16] presents a regionally adjustable ground motion prediction equation (GMPE), known as the component attenuation model (CAM), by which a diversity of crustal conditions can be covered in one model. In addressing the challenge of validating a GMPE for use in an area where instrumental data are scarce, Modified Mercalli intensity (MMI) data inferred from peak ground velocity values predicted by CAM are compared with the records of MMI of past earthquake events, as reported in historical archives. South-Eastern Australia and South-Eastern China are the two study regions used in this article for demonstrating the viability of CAM as a ground motion prediction tool in an intraplate environment.

- The paper "Comparison of Earthquake-Triggered Landslide Inventories: A Case Study of the 2015 Gorkha Earthquake, Nepal" by S.R. Meena and S. Tavakkoli Piralilou [17] presents an overview of the impact of methodology selection and outlines the limitations and advantages of different remote sensing and mapping techniques for landslide inventorying: a case study of the 2015 Gorkha earthquake, Nepal. After the main event on 25 April 2015, researchers around the world mapped the landslides induced by this earthquake. In this research, the authors compared four of these published inventories qualitatively and quantitatively using different techniques. Two principal methodologies, namely the cartographical degree of matching and frequency area distribution (FAD), were optimized and applied to evaluate inventory maps.

- The paper "Dynamics of the Zones of Strong Earthquake Epicenters in the Arctic-Asian Seismic Belt" by L.P. Imaeva [18] presents a comprehensive study of the Russian Arctic region to clarify the features and types of seismotectonic deformation of the crust in the Arctic-Asian Seismic Belt, specifically in the zones of strong earthquakes in the Laptev Sea Segment, the Kharaulakh Segment, and the Chersky Seismotectonic Zone. The authors have analyzed modern tectonic structures and active fault systems, as well as tectonic stress fields reconstructed by tectonophysical analysis of 
the Late Cenozoic faults and folds. A set of models has been constructed for the studied segments of plate boundaries with account of the dynamics of the regional geological structures. The models can give a framework for the assessment of potential seismic risks of seismicity-generating structures in the Russian Arctic region.

- The paper "Undrained Cyclic Laboratory Behavior of Sandy Soils" by Castelli et al. [19] presents the complex cyclic shear stress path experienced by the soil during an earthquake, which could also induce the liquefaction phenomena. The authors performed a detailed geological and geotechnical characterization of the area through in situ and laboratory tests, including seismic dilatometer Marchetti tests (SDMTs), the combined resonant column (RCT) and cyclic loading torsional shear tests (CLTSTs), and undrained cyclic loading triaxial tests (CLTxTs). The paper presents the results of cyclic triaxial tests carried out on isotropically consolidated specimens of a sandy soil.

Acknowledgments: The Guest Editors thank all the Authors, the Geosciences' Editors, and the reviewers for their appreciable contributions and commitment to this Special Issue. Special thanks go to Richard Li, Geosciences' Assistant Editor, for his dedication to this project and his valuable collaboration in the setup, promotion, and management of the Special Issue.

Conflicts of Interest: The authors declare no conflict of interest.

\section{References}

1. Michetti, A.M.; Esposito, E.; Guerrieri, L.; Porfido, S.; Serva, L.; Tatevossian, R.; Vittori, E.; Audemard, F.; Azuma, T.; Clague, J.; et al. Environmental Seismic Intensity scale-ESI 2007. Mem. Descr. Carta Geol. D'Ital. 2007, 74, 7-23.

2. Serva, L. History of the Environmental Seismic Intensity Scale ESI-07. Geosciences 2019, 9, 210. [CrossRef]

3. Tuttle, M.P.; Hartleb, R.; Wolf, L.; Mayne, P.W. Paleoliquefaction Studies and the Evaluation of Seismic Hazard. Geosciences 2019, 9, 311. [CrossRef]

4. Silva, P.G.; Rodríguez-Pascua, M.A.; Giner Robles, J.L.; Élez, J.; Pérez-López, R.; Davila, M.B.B. Catalogue of the Geological Effects of Earthquakes in Spain Based on the ESI-07 Macroseismic Scale: A New Database for Seismic Hazard Analysis. Geosciences 2019, 9, 334. [CrossRef]

5. King, T.R.; Quigley, M.; Clark, D. Surface-Rupturing Historical Earthquakes in Australia and Their Environmental Effects: New Insights from Re-Analyses of Observational Data. Geosciences 2019, 9, 408. [CrossRef]

6. Lippiello, E.; Cirillo, A.; Godano, C.; Papadimitriou, E.; Karakostas, V. Post Seismic Catalog Incompleteness and Aftershock Forecasting. Geosciences 2019, 9, 355. [CrossRef]

7. Chunga, K.; Livio, F.A.; Martillo, C.; Lara-Saavedra, H.; Ferrario, M.F.; Zevallos, I.; Michetti, A.M. Landslides Triggered by the 2016 Mw 7.8 Pedernales, Ecuador Earthquake: Correlations with ESI-07 Intensity, Lithology, Slope and PGA-h. Geosciences 2019, 9, 371. [CrossRef]

8. Caccavale, M.; Sacchi, M.; Spiga, E.; Porfido, S. The 1976 Guatemala Earthquake: ESI Scale and Probabilistic/Deterministic Seismic Hazard Analysis Approaches. Geosciences 2019, 9, 403. [CrossRef]

9. Naik, S.P.; Kim, Y.-S.; Kim, T.; Su-Ho, J. Geological and Structural Control on Localized Ground Effects within the Heunghae Basin during the Pohang Earthquake (MW 5.4, 15th November 2017), South Korea. Geosciences 2019, 9, 173. [CrossRef]

10. Grützner, C.; Walker, R.; Ainscoe, E.; Elliott, A.; Abdrakhmatov, K. Earthquake Environmental Effects of the 1992 MS7.3 Suusamyr Earthquake, Kyrgyzstan, and Their Implications for Paleo-Earthquake Studies. Geosciences 2019, 9, 271. [CrossRef]

11. Konovalov, A.; Gensiorovskiy, Y.; Lobkina, V.; Muzychenko, A.; Stepnova, Y.; Muzychenko, L.; Stepnov, A.; Mikhalyov, M. Earthquake-Induced Landslide Risk Assessment: An Example from Sakhalin Island, Russia. Geosciences 2019, 9, 305. [CrossRef]

12. Tumurbaatar, Z.; Miura, H.; Tsamba, T. Site Effect Assessment in Ulaanbaatar, Mongolia through Inversion Analysis of Microtremor H/V Spectral Ratios. Geosciences 2019, 9, 228. [CrossRef]

13. Yang, H.-C.; Hu, G.; Chen, M.-H. Bayesian Variable Selection for Pareto Regression Models with Latent Multivariate Log Gamma Process with Applications to Earthquake Magnitudes. Geosciences 2019, 9, 169. [CrossRef] [PubMed] 
14. Gitis, V.G.; Derendyaev, A.B. Machine Learning Methods for Seismic Hazards Forecast. Geosciences 2019, 9, 308. [CrossRef]

15. Akamatsu, T.; Yamamoto, K. Suitability Analysis for the Emergency Shelters Allocation after an Earthquake in Japan. Geosciences 2019, 9, 336. [CrossRef]

16. Tang, Y.; Lam, N.; Tsang, H.-H.; Lumantarna, E. Use of Macroseismic Intensity Data to Validate a Regionally Adjustable Ground Motion Prediction Model. Geosciences 2019, 9, 422. [CrossRef]

17. Meena, S.R.; Tavakkoli Piralilou, S. Comparison of Earthquake-Triggered Landslide Inventories: A Case Study of the 2015 Gorkha Earthquake, Nepal. Geosciences 2019, 9, 437. [CrossRef]

18. Imaeva, L.P.; Imaev, V.S.; Koz'min, B.M. Dynamics of the Zones of Strong Earthquake Epicenters in the Arctic-Asian Seismic Belt. Geosciences 2019, 9, 168. [CrossRef]

19. Castelli, F.; Cavallaro, A.; Grasso, S.; Lentini, V. Undrained Cyclic Laboratory Behavior of Sandy Soils. Geosciences 2019, 9, 512. [CrossRef]

(C) 2020 by the authors. Licensee MDPI, Basel, Switzerland. This article is an open access article distributed under the terms and conditions of the Creative Commons Attribution (CC BY) license (http://creativecommons.org/licenses/by/4.0/). 